\title{
Barriers and facilitators to the implementation of nurse's role in primary care settings: an integrative review
}

Erica Busca ${ }^{1}$, Alessia Savatteri ${ }^{2}$, Tania Lorenza Calafato ${ }^{3}$, Beatrice Mazzoleni ${ }^{4}$, Michela Barisone ${ }^{1 *}$ and Alberto Dal Molin 5

\begin{abstract}
Background: The rapid evolution of the epidemiological picture and the recent SARS-COV-2 pandemic has expressed the vulnerabilities of health systems and focuses attention on the population's needs.

The nurse's figure in the care teams is universally identified; however, the implementation of the role within some care settings turns out to be complex and challenging. This integrative review aims to identify the barriers and facilitators in implementing the role of the nurse in primary care settings.

Methods: An integrative review was conducted on the Medline and Cinahl databases until 9 June 2020. Qualitative, quantitative, and Mixed-method research studies were selected to identify studies related to the barriers and facilitators of the nurse's role in nursing facilities' primary care. For the extraction of the results, the Consolidating Framework for Research Implementation (CFIR) was used to identify the factors that influence implementation in health care.

Results: Following the duplicates' removal, the search identified 18,257 articles, of which 56 were relevant to the inclusion criteria; therefore, they were included in the summary.

The selected studies were conducted in thirteen countries, most from Oceania, Europe, North America, Latin America, and the Caribbean.

The barriers reported most frequently concern the nursing profession's regulatory and regulatory aspects within the contexts of care, cultural and organizational aspects, training, and the transfer of specific skills, which were previously designated to doctors.

The facilitators are mainly linked to the nurse's adaptability to the various contexts of care, recognizing the patient's role, and the desire to develop multidisciplinary and effective working groups to respond to the health needs of the population in primary care contexts.

Conclusion: This review highlighted the main barriers and facilitators in implementing the nurse's role in primary care settings. These results offer useful elements for stakeholders to identify effective strategies in preparing programs and activities for implementing the nurse's role, acting on the elements identified as barriers and favouring the aspects that emerge as facilitators.
\end{abstract}

\footnotetext{
* Correspondence: michela.barisone@uniupo.it

'Department of Translational Medicine, University of Piemonte Orientale, Via P. Solaroli, 17, 28100 Novara, Italy

Full list of author information is available at the end of the article
}

(c) The Author(s). 2021 Open Access This article is licensed under a Creative Commons Attribution 4.0 International License, which permits use, sharing, adaptation, distribution and reproduction in any medium or format, as long as you give appropriate credit to the original author(s) and the source, provide a link to the Creative Commons licence, and indicate if changes were made. The images or other third party material in this article are included in the article's Creative Commons licence, unless indicated otherwise in a credit line to the material. If material is not included in the article's Creative Commons licence and your intended use is not permitted by statutory regulation or exceeds the permitted use, you will need to obtain permission directly from the copyright holder. To view a copy of this licence, visit http://creativecommons.org/licenses/by/4.0/. The Creative Commons Public Domain Dedication waiver (http://creativecommons.org/publicdomain/zero/1.0/) applies to the data made available in this article, unless otherwise stated in a credit line to the data. 
Keywords: Registered nurse, Nurse practitioner, Advanced nurse practitioner, Family nurse practitioner, Family health nurse, Community health nurse, District nurse, Public health nurse, Primary care, Community care

\section{Background}

In recent years, the progressive epidemiological changes in large part due to the aging population, the increase in non-communicable diseases (NCDs), and the recent COVID-19 pandemic have necessarily led to a rethinking of the people's needs for assistance, redefining the models of care for the most vulnerable age groups $[1,2]$.

NCDs, such as heart disease, stroke, cancer, diabetes, and chronic lung disease, have become the leading cause of disability and death worldwide [3]. In 2017, one in eight people was aged 60 years or older, and it is estimated that there will be one person over 60 for every six and five people by 2030 and 2050, respectively [4].

To counteract this emerging public health problem, the World Health Assembly of the World Health Organization (WHO) has launched an initiative named Decade of Healthy Aging 2020-2030 [5] aimed to promote autonomy among the elderly while designing new patient-focused care models and identifying long-term care needs. If no action is taken, health spending, tax burden, and health inequalities, especially in low and middle-income countries, are all expected to increase significantly in the nearby future [6]. Thus, there is a growing consensus among citizens that strengthening the resilience of national healthcare systems will help mitigate the impact of the epidemiological changes.

The recent COVID-19 pandemic has further increased the complexity of care and created an even greater demand for chronic care services carried out at the patient's home $[7,8]$. This has led to an in-depth reflection on current models of care, raising the important issue of what role nurses should play to help meet the increasingly complex healthcare needs of the community.

In most countries, one of the main reasons for developing and implementing the nurse's role is to improve access to healthcare, especially in those settings where medical resources are scarce [9]. Another equally important reason for developing nursing nurses' roles is that this process is critical to further promote the quality of care by providing support to chronic patients through on-site follow-up activities, thereby reducing hospital admissions and readmissions [10].

However, the implementation of nursing roles is not unique at an international level. There are, in fact, cultural, regulatory, and organizational factors specific to individual contexts that should be taken into account besides the nursing skill-mix level [11]. Thus, the epidemiological evolution we are witnessing requires the redefinition of the roles of the various professionals involved in primary care assistance aimed to enhance professional collaboration and, at the same time, redefine the nursing skills [12]. In particular, the heterogeneity of nursing contexts and roles at the international level calls for the need to define new strategies for implementing nursing roles in primary care settings [13].

In light of these considerations, the WHO guidelines have set the standards to achieve a sustainable primary healthcare system in line with the legislation, organization, and health priorities of each individual nation, prioritizing disease prevention and promoting health. By offering effective services in the field of prevention, promotion, treatment, rehabilitation, and palliative care, the ambitious goal of this initiative is that of fulfilling people's health needs throughout their lives in a sustainable way [14]. Therefore, it is becoming increasingly clear how theoretical and clinical skills acquired by nurses through training and retraining will be key to the implementation of care roles and the improvement of health outcomes in primary care settings [15].

However, a large body of literature has pointed to several factors influencing the effectiveness of nurse's role implementation in the primary care settings [13]. Thus, the purpose of this study was to identify the facilitators and barriers encountered during nurse's role implementation from the stakeholders' perspective (i.e., nurses, physicians, and patients).

\section{Methods \\ Study design}

The research question was addressed through an integrative review method that allows using original qualitative research and quantitative research on barriers to and facilitators of nurse's role implementation in primary care settings [16]. This integrative review combines data from studies conducted using various designs and provides an in-depth analysis of this complex theme. The Preferred Reporting Items for Systematic Review and Meta-Analyses (PRISMA) was used [17].

\section{Search strategy}

The search was performed using the two databases Medline and CINAHL, up to the 9th of June 2020. We developed search strategies for each database (Additional file 1). Search strategies consisted of keywords and controlled vocabulary terms (Table 1). We also scanned reference lists of all included studies and 
Table 1 Terms used in search strategies

\begin{tabular}{ll}
\hline MeSH terms* & Relevant key words** \\
\hline Nurse practitioners & Nurse practitioner, advanced nurse practitioner \\
$\begin{array}{l}\text { Nurses, Community Health } \\
\text { Family Nurse Practitioners }\end{array}$ & Family nurse practitioner, family health nurse, community health nurse, district nurse, public health nurse, rural nurse \\
$\begin{array}{l}\text { Nurses, Public Health } \\
\text { Primary health care }\end{array}$ & Primary care, community care, community health care, district \\
Community Health Services & \\
Nurse's Role & Nurse role \\
\hline
\end{tabular}

*MeSH terms were combined in three different searches using Boolean operators AND, and the search terms within each box were combined with OR

**Keywords were searched using truncation and phrase symbols when appropriate

key references (i.e., relevant reviews). We limited our searches to English and Italian for feasibility reasons.

\section{Eligibility criteria}

We included primary studies that used qualitative or quantitative study designs and mixed methods approaches. We excluded case studies, editorials, commentaries, and reviews. We included studies that focused on stakeholders' perceptions of how nurse's role implementation is developed. Stakeholders include nurses, general practitioners, patients, and other individuals or professional categories directly or indirectly affected by nurse's role implementation in primary care settings. We included any types of nurses working in primary care settings. Primary care was defined as follows: "The provision of universally accessible, integrated personcentred, comprehensive health and community services provided by a team of professionals accountable for addressing a large majority of personal health needs. These services are delivered in a sustained partnership with patients and informal caregivers, in the context of family and community, and play a central role in the overall coordination and continuity of people's care" [18].

We excluded studies focused on nurses or nursing practice concepts conducted in settings other than primary care (e.g., hospital emergency departments). Studies conducted in mixed settings were included if the results related to primary care could be clearly identified among the overall findings.

\section{Selection of studies}

Two review authors independently scanned each title and abstract obtained from the electronic databases to determine if these fulfilled the inclusion criteria. Then, full-text publications of the selected studies were retrieved to confirm they met inclusion criteria. At all stages, we resolved any disagreements between the authors via discussion or, if required, by seeking a third reviewer's opinion.

\section{Data extraction}

We perform data extraction using the Consolidating Framework for Research Implementation (CFIR). The CFIR structure supports the exploration of essential factors encountered during implementation through formative evaluations [19] (Table 2). The framework emphasizes the multi-level influences on nurse's role implementation, from external influencers to organizational and core implementation process components, and provides a pragmatic organization of constructs.

We also extracted information on study characteristics (i.e., author, date of publication, country, aims, study design, study population, and study setting) and a description of the nurse's role (i.e., training and details about any interventions delivered).

\section{Data synthesis}

Three review authors read the selected studies and applied the CFIR framework, moving between the framework themes. Relevant data of each theme were extracted from all primary data sources. The review author, after discussing each emerging theme, definition, and boundaries, revised and compiled the CFIR framework in line with the emerging categories.

\section{Quality appraisal}

Whittemore and Knafl (2005) state that assessing the quality of the included evidence is not essential in a supplementary review [16]. All studies meeting the inclusion criteria, regardless of their methodological quality, were retained in the review to examine all evidence of the factors that influenced the nursing role implementation in practice settings.

\section{Results}

\section{Characteristic of the included studies}

We screened 18,257 records and considered 283 full texts for inclusion in this integrative review. Fifty-six papers met the inclusion criteria [20-75], and six papers 
Table 2 Descriptions of CFIR domains

\begin{tabular}{|c|c|}
\hline Domain & Definition \\
\hline $\begin{array}{l}\text { Intervention } \\
\text { characteristics }\end{array}$ & $\begin{array}{l}\text { The characteristics of the intervention being implemented include whether the intervention is perceived to be developed } \\
\text { external or internal to the organization, there is evidence supporting its effectiveness, and its implementation will be } \\
\text { advantageous to its alternatives. Other characteristics include how the intervention is presented, its adaptability, } \\
\text { complexity and whether it can be tested on a smaller scale. }\end{array}$ \\
\hline Outer setting & $\begin{array}{l}\text { The external context of the organization includes patient needs and the ability to meet them, networks with other } \\
\text { organizations, pressure to implement the intervention and external policies and incentives to adopt the intervention. }\end{array}$ \\
\hline Inner setting & $\begin{array}{l}\text { Features of the organization including its structural characteristics (such as size, age of the organization and division of } \\
\text { labour), networks and communication (such as connections and information sharing between individuals, units and } \\
\text { services), cultural norms and values, implementation climate, organizational capacity and readiness for change. }\end{array}$ \\
\hline $\begin{array}{l}\text { Characteristics of } \\
\text { individuals }\end{array}$ & $\begin{array}{l}\text { Staff knowledge and belief about the intervention, their ability to execute their respective aspects of the implementation, } \\
\text { and their individual stage of change. Other characteristics include individual identification with the organization and other } \\
\text { personal attributes. }\end{array}$ \\
\hline Process & $\begin{array}{l}\text { Active change process, the purpose of which is to promote uptake of the intervention by the organization. This is } \\
\text { influenced by the level of planning prior to implementation, and engaging organization stakeholders through appointing } \\
\text { implementation leaders and champions of the intervention. This includes the ability to execute the implementation of the } \\
\text { intervention as planned and to continuously reflect on and evaluate the quality of implementation and intervention as it } \\
\text { progresses. }\end{array}$ \\
\hline
\end{tabular}

$[30,45,47,49,59,61]$ derived from three unique studies (Fig. 1).

Studies were conducted across 13 countries: 9 studies in Oceania [26, 32, 35, 44, 60, 66, 68-70], one in Asia [36], 21 in Europe [20-22, 29, 33, 34, 41-43, 46, 51-54, $57,58,62,65,67,73,74], 24$ in North America [23-25, $27,28,30,31,37-40,45,47-50,55,56,59,61,64,71$, 72, 75], and one in Latin America and the Caribbean [63]. Thirty-six studies employed a qualitative design either descriptive $[20,22,25,29,31,36,38,41-44,46,48$, $52-59,61,62,64,69,71,73]$, grounded theory [51, 70, 74], phenomenological approach [32, 40], or ethnographic research $[26,35,39]$. Fourteen studies used a quantitative design -cross sectional approach- $[21,24$, $27,28,30,34,37,45,47,49,60,63,72,75]$, while 6 used a mixed method [23, 33, 50, 65, 66, 68].

Participants included registered nurses, nurse practitioners, general practitioners, health leaders (chairpersons of health boards), managers, nursing leaders, key informants (e.g., university employees, Ministry of Health employees, policy makers), health and social care professionals, administrators, and patients (Additional file 2).

\section{Nursing role and tasks}

A number of studies took into account nurse practitioners working in advanced roles (APN) [21, 23, 24, 26-31, 35, 37-42, 44-56, 59, 61-64, 66-69, 72, 74, 75] and registered nurses working in advanced practice levels or with specialist designations $[20,22,25,32,33$, $36,42,43,57,58,60,65,70,71,73]$.

In these studies, the title "registered nurse" was often replaced by the following definitions: "community nurse", "family health nurse", "public health nurse", "mental health nurse", "community matron", "mental health nurse of community", or "district nurse".
A number of studies specified nurses' qualifications, ranging from bachelor's degree to post-graduate qualification attainment (e.g., master's degree, doctorate in nursing) $[24-31,35,36,38-42,44,48,49,51-53,56,63$, $64,66-69,72,74,75]$.

The main tasks carried out by nurse practitioners (NPs) and registered nurses (RNs) are illustrated in Fig. 2. All nurses worked in primary care settings, including general practice, health care centers, and rural/remote areas.

\section{Factors influencing implementation}

The frequency of identification of barriers and facilitators in each domain is summarized in Table 3, while the specific determinants can be found in Additional file 3.

The integrative review identified similar barriers and facilitators for both advanced role and a general nursing role. When factors are more referred to APN, we clearly indicated in the text. The main factors are listened below.

\section{Intervention characteristics \\ Barriers}

With regard to the CFIR domain, nurses pointed to four main factors affecting nurses' role implementation: 1) scope of practice; 2) nursing workload; 3) nursing education; and 4) funding.

Restrictions of nurse scope of practice and autonomy was the most frequently reported barrier to APN role implementation $[21,23,24,28,31,35,44,45,47,48,53$, 55, 56]. Arbitrary laws [31], state restriction, hospital regulations [28], and health care professionals' expectations $[35,55]$ all contributed to restrict the independence of nurses and limit the full potential of their roles. For instance, some regulations required nurses to be supervised by physicians when exercising their prescriptive 


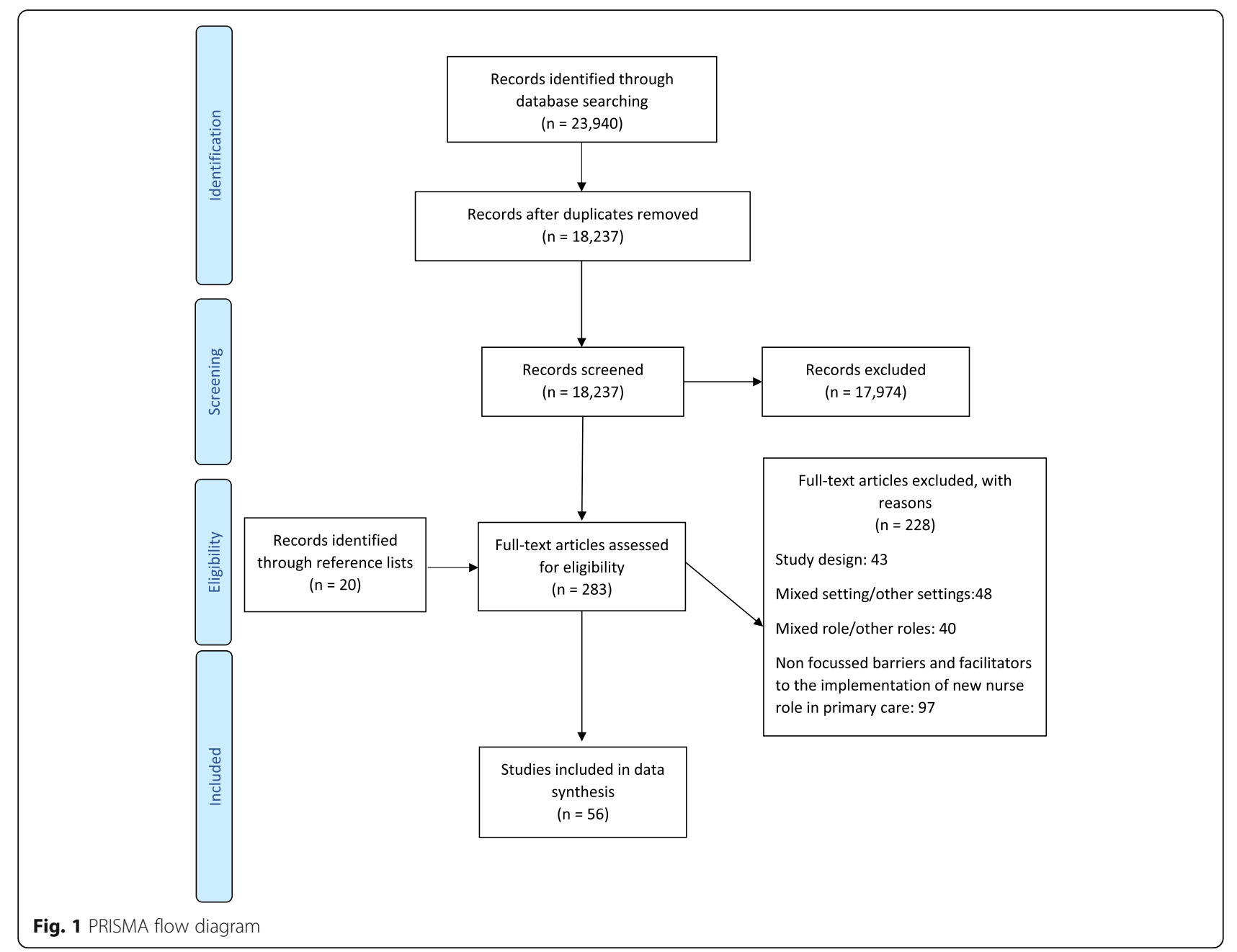

authority [38-40]. In addition, physicians often advocated the use of certain protocols [21] or required their supervision [45] through collaborative practice agreements $[23,31]$.

Other studies identified excessive caseload numbers and complex cases as barriers [25, 30, 32, 57, 58] to care provision [33, 71]. Furthermore, patient care complexity, alongside other non-clinical functions-mainly administrative and/or bureaucratic-, further increases the nurses' workload [57].

Education was identified as a barrier to nurse's role development in 13 studies. In particular, nurses expressed their concerns about the educational programs available to them, often questioning the adequacy of the training received $[41,56,63]$, deemed insufficient to help them develop the skills required $[25,45,62,65$, 70]. Nurses also complained about the existence of barriers to training opportunities and ongoing education [50], such as the lack of information regarding course availability [26], the difficulty in taking time off work to attend courses [26, 54], the need to travel long distance to reach the location where the course was being taught [32], and the lack of funding to cover education-related expenses $[26,51]$. In regard to the latter, funding to sustain the nurse position was regarded as a barrier to nurse's role implementation across 11 studies [21, 23, $36,39,42-44,50,52,54,66]$.

\section{Facilitators}

Nurses mainly indicated two facilitators of nurse's role implementation: $i$ ) adaptability of the nursing role to the existing context [53] and ii) trialability [46]. Education and training were also reported as factors facilitating nurse's role implementation. Educational resources such as master's degree programs were generally thought to improve nurses' clinical skills and provide job retraining opportunities, especially in primary care settings $[26,29$, 36, 46]. Moreover, additional experiences, such as residency or fellowship programs after graduation, were felt as supporting role transitions in primary care [30]. One study reported that motivating nurses to study represented an additional important factor in attaining 


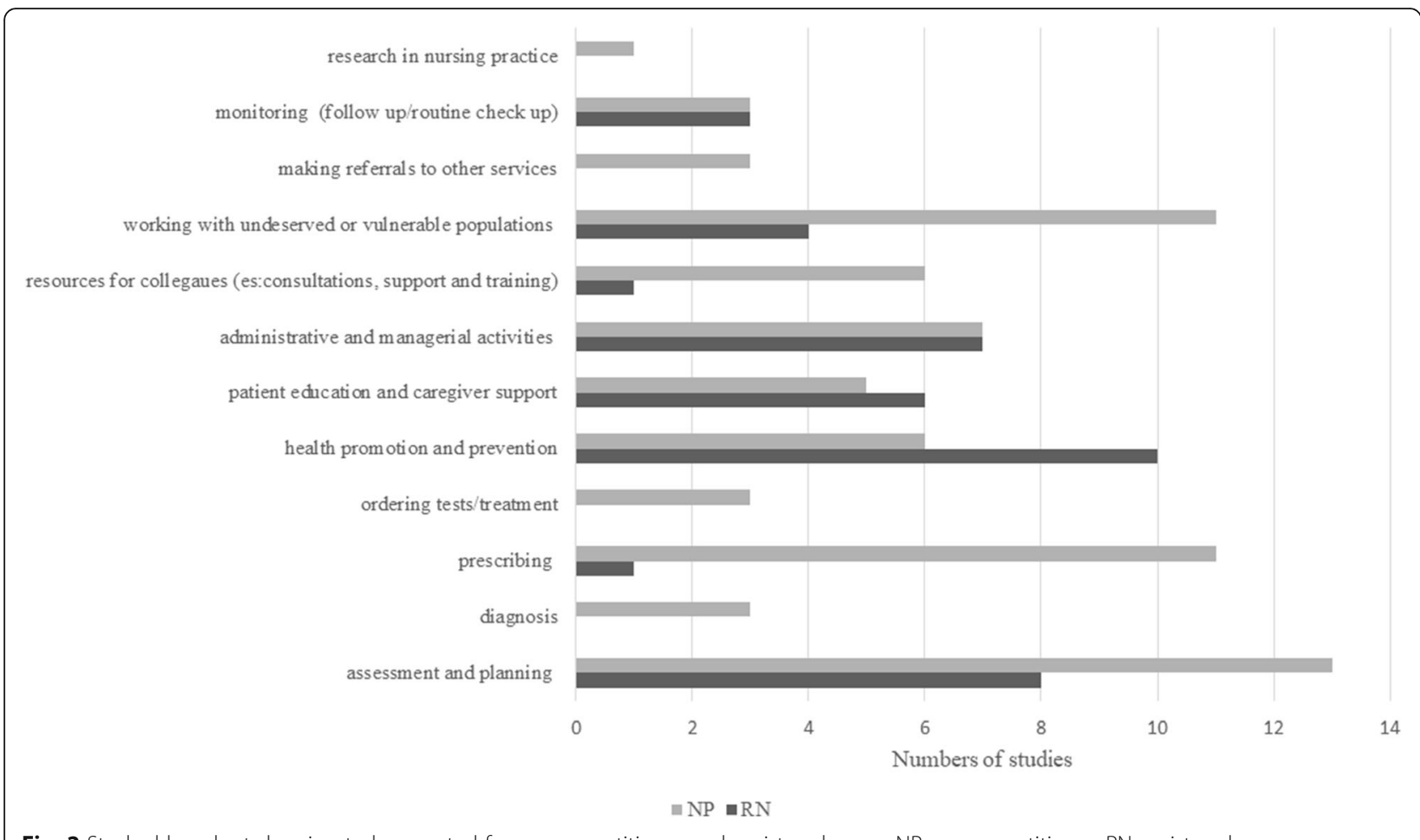

Fig. 2 Stacked bar chart showing tasks reported for nurse practitioner and registered nurse. NP-nurse practitioner, RN-registered nurse

advanced practice levels [62]. Another facilitator was represented by nurses being satisfied with their full scope of practice [24-29] or working autonomously [27, 30-33]. Other facilitators included expanding nurse's practice to carry out tasks normally performed by physicians $[29,35,36]$ or putting nurses in charge of the communications between the patient and other care providers $[29,34]$.

\section{Outer setting}

\section{Barriers}

Patient-related factors were reported as key barriers across several studies. From a patient perspective, one of the main factors negatively impacting the acceptance of the nursing role was the lack of knowledge and understanding of such role $[42,48,56,68,69,72]$. Other factors included negative patients' prior experience [68] and patients' preference and medical condition $[68,69]$.

Five studies analyzing external policies from a nurse perspective identified prescribing restrictions [38-40] and remuneration policies $[46,48]$ as barriers to nurse's role implementation.

\section{Facilitators}

Also in this case, most of the facilitators identified were related to patient-related factors. Generally, the care provided by nurses was regarded by patients as highly satisfactory $[21,41,50,65,67]$ due to the many advantages it afforded, such as a more patient-centered communication $[46,50,62,68,69]$ and the provision of personalized solutions to better meet their needs $[25,35$, 36, 57]. Patients also described how their access to care would be quicker and easier $[34,50]$. Several studies emphasized the patients' acceptance of the nursing role [23, $36,48,63,66,68]$ thanks to knowledge and role recognition $[59,61]$ and nurse-community connection [50].

\section{Inner setting}

Barriers

Barriers identified across studies were linked to organizational factors and were reported by different health care professionals (i.e., nurses, managers, and doctors).

Recruitment and retention of nurses were viewed as barriers due to the difficulty in recruiting and retaining qualified nurses [20, 29, 62, 65]. Organizational factors, such as lack of long-term human resource planning [52] and career opportunities [62] as well as uncertain employment $[20,26,29,55]$, all negatively influenced nursing role implementation. This barrier quite often led to high staff turnover among nurses [20] and increased intention to leave, especially among newly hired nurses $[20,72]$.

A few studies referred to the organization's culture, hierarchical structure [29, 36, 48], and difficulties in adopting a flexible approach to service delivery [73] as 
Table 3 Barriers and facilitators in each CFIR domain

\begin{tabular}{|c|c|c|c|}
\hline \multirow[t]{2}{*}{ Domain } & \multirow[t]{2}{*}{ Themes } & \multirow{2}{*}{$\begin{array}{l}\text { Barriers } \\
\mathrm{N}^{\circ} \text { of studies }(\%)\end{array}$} & \multirow{2}{*}{$\begin{array}{l}\text { Facilitators } \\
\mathrm{N}^{\circ} \text { of studies (\%) }\end{array}$} \\
\hline & & & \\
\hline \multirow[t]{6}{*}{ 1. Intervention Characteristic } & scope of practice & $16(28,6)$ & $13(23,2)$ \\
\hline & adaptability & 0 & $1(1,8)$ \\
\hline & trialability & 0 & $1(1,8)$ \\
\hline & workload & $7(12,5)$ & 0 \\
\hline & education & $14(25)$ & $7(12,5)$ \\
\hline & funding & $11(19,6)$ & $2(3,6)$ \\
\hline \multirow[t]{2}{*}{ 2. Outer setting } & patient factors & $6(10,7)$ & $21(37,5)$ \\
\hline & external policies & $5(8,9)$ & 0 \\
\hline \multirow[t]{5}{*}{ 3. Inner setting } & culture & $9(16,1)$ & 0 \\
\hline & workforce and organization & $10(17,9)$ & $8(14,3)$ \\
\hline & communication & $8(14,3)$ & $7(12,5)$ \\
\hline & implementation climate & $26(46,4)$ & $28(50)$ \\
\hline & resources & $9(16,1)$ & $1(1,8)$ \\
\hline \multirow[t]{4}{*}{ 4. Individual characteristics } & team acceptance & $30(53,6)$ & $24(42,9)$ \\
\hline & self confidence & $4(7,1)$ & $3(5,4)$ \\
\hline & personal attributes & $1(1,8)$ & $2(3,6)$ \\
\hline & individual stage of change & $2(3,6)$ & 0 \\
\hline \multirow[t]{4}{*}{ 5. Process } & planning & $2(3,6)$ & $4(7,1)$ \\
\hline & stakeholder engagement & $4(7,1)$ & $8(14,3)$ \\
\hline & development and implementation & $2(3,6)$ & $8(14,3)$ \\
\hline & evaluation & $4(7,1)$ & $2(3,6)$ \\
\hline
\end{tabular}

main barriers to nurse's role implementation. The nursing practice was overshadowed by the more dominant medical model [51, 58, 61, 63], prioritizing medical solutions to health problems rather than promoting patient wellness-centered care [35, 43].

The nature and quality of communications were among the environmental factors regarded as barriers to information access and support in rural areas. These were mainly due to isolation [32, 33], poor internet connection, and lack of electricity to run equipment [64]. Also, lack of information sharing between staff administrators and health professionals was associated with negative consequences [38, 64, 72]. Some studies reported that lack of shared understanding of the patients' needs affected the team's ability to provide care [57, 70, 71].

Unfavorable implementation climate was the most frequently reported barrier to nurse's role implementation. The professional relationship between health workers and other inter-professional workers [22, 41, 42, 56] along with the lack of regulation of nursing role [22, 41, 42] hindered nurse's role implementation [42]. In particular, the lack of professional collaboration was described as a strong obstacle to nurse's role development $[24,29,39,41,42,48,67,74]$, with nurses emphasizing how counselors and secondary care providers would often refuse their referrals $[24,39$, $41,42,48,67,74$ ] or choose not to share with them critical information [41]. Among the causes of professional collaboration breakdown was the lack of support from physicians, managers, and administrative staff $[26,30,33,43,44,64,72]$. In general, nurses felt that they had not received enough collegial and managerial support [26], the same level of access to resources as that granted to physicians $[38,40]$, or the same respect as that paid to their peers [30, 72]. Consequently, nurses complained about the invisibility of their role in the community $[22,38,72]$.

Professional isolation of nurses was reported as being an additional barrier in seven studies $[24,30,32,33,50$, $51,64]$ due to the lack of integration with other health professionals in the workplace [32, 51]. These studies also pointed to the fact that the common goals were neither shared with nor clearly communicated to nurses by their employers [30, 32]. Furthermore, the contractual context was also shown to influence the climate as the 
lack of a reward and incentive system [20,30] negatively affected the nurses' morale [30, 55]. Lastly, according to several studies, the lack of resources was among the barriers to nurse's role implementation $[20,29,34,36,38$, $39,56,57,70]$.

\section{Facilitators}

Facilitators mainly referred to challenges for workforce development, nature and quality of communication, and implementation climate. Specifically, nurses reported that workforce challenges in primary care settings, such as changing patient case-mix [20,42] and shortages of primary care providers $[26,50]$, favored nurse's role development. Nurses also reported that communication strategies and technology helped them establish a relationship between primary and secondary care. On-call systems connecting healthcare professionals, telemedicine equipment, and team sharing of patient information, including case-reviews, were all crucial to the continuity of care [59, 64]. This is consistent with findings from other studies showing the importance of regular communication-preferably using the same electronic patient records-in the collaboration and coordination among health care professionals [34, 42, 50, 56].

Professional trust, mutual respect, and a close doctornurse relationship were also seen as facilitators of nurse's role implementation and collaboration among nurses [31, 32, 42, 46, 50, 51, 56, 61]. In addition, interprofessional relationships and team working played a key role in facilitating nurse's role development $[25,27$, $35,39,41,43,48,58]$. This process was even more pronounced when nurses felt trusted and supported by physicians, pharmacists, managers, and colleagues [23, 24, $26,29,31,38,48,64,71]$. Also mentoring, mainly from doctors and colleagues, was central to providing support during transition into the new role $[26,30,39,41,44$, 64].

\section{Characteristics of individuals \\ Barriers}

Barriers identified across studies were primarily linked to poor team acceptance and low self-esteem among nurses. For instance, physicians' resistance [23, 42, 56] was associated with lack of role clarity and concern about nursing practice [24-26, 30, 36, 38, 43-51, 66, $72]$. Moreover, there was consensus among nurses, administrative staff, and team members that healthcare professionals were often not fully aware of the scope of the nursing practice $[21,28-30,39,45,52,53,66]$. In addition, physicians expressed lack of trust in nurses' skills and knowledge [29, 36, 45, 47, 51, 54, 66, 72] and were concerned about their workload, nurse-doctor competition, and fragmentation and duplication of services $[51,52,66]$, especially when the two roles were perceived as overlapping. The other major barrier was nurse self-doubt $[44,47]$. In one study, nurses reported that they felt uncertain when colleagues did not regarded them as a resource [61].

\section{Facilitators}

Clarity and understanding of the nursing role were identified as crucial factors to gain the physicians' acceptance [61]. The nursing role was more easily understood once doctors had previous nurse-doctor collaboration experiences [23, 26, 41, 52].

From a physician's perspective, there were some motivations to employ nurses in primary care, including complementary relationships [52, 74] and enhanced quality and delivery of healthcare [28, 42, 66, 67]. Many physicians were satisfied with their collaboration with nurses [31, 34, 45, 50]. Consistently, other studies reported that nurse's role in primary care settings reduced the physicians' workload [21, 42, 46, 62], allowing these latter to focus on other more complex cases [42, 45]. Fittingly, nurses felt that they were instrumental in improving quality of care and increasing patient safety [31, 33, $35,46,48,52,59,62]$ and considered their work to be valuable and worthy. Nurses expressed their satisfaction in providing more than patient care compared to other healthcare professionals [25, 41]. Finally, nurses were confident in their skills and knowledge [49] and aware of their own limits $[31,46]$.

\section{Process \\ Barriers}

Process barriers were related to the lack of planning regarding nurse's role utilization. In particular, it was unclear how care services would be adapted to meet changing needs $[33,73]$. Furthermore, nurses often complained about the absence of clear leadership [71], topdown approach [56], and evaluation criteria. In two studies, nurses admitted their difficulties in identifying suitable tools to measure the outcome of their contributions $[25,59]$.

\section{Facilitators}

Few studies highlighted the importance of developing an implementation plan with a focus on workforce integration. Review of the existing nursing service, definition of roles and functions, and team involvement were useful considerations that guided planning $[43,56,65]$. Factors associated with better role development and integration were nurses' involvement in developing their role (e.g., drafting job description) $[24,60]$, support from management, and strategic alliance with health authorities [24, $59,61]$. Universities were identified as external agents to the organization formally influencing role development 
[63]. The last facilitator was linked to the evaluation process. Nurses expressed the need to evaluate the effectiveness of their contribution [25] and identified research and audit mechanisms as resources to measure their professional outcome [41].

\section{Discussion}

This integrative review includes 56 studies addressing barriers and facilitators during nurse's role implementation in primary care settings. We have analyzed a large volume of information and experiences from the various stakeholders and identified several emerging factors influencing nurse's role implementation strategies. Although we could not separate each contribution due to the miscellaneous participation in the studies, the different stakeholders' perspectives allowed us to identify the specific barriers of and facilitators to nurse's role implementation. These are summarized below.

\section{Barriers}

Our synthesis shows that the major emerging themes regarding the barriers to nurse's role implementation pertain to the following variables: $i$ ) the characteristics of the intervention; ii) the characteristics of the individuals; and iii) the inner setting of the healthcare professionals' organization. Limiting factors were equally distributed among RNs and NPs, the two most represented nursing roles in primary care settings. Barriers related to the characteristics of the intervention are mainly due to the limited availability of and access to special education, which results in nurses lacking sufficient knowledge and skills to work in primary healthcare settings. Furthermore, key determinants of independent practice such as legislations and regulations also appear to influence nurse's role implementation. Previous report showed that the restrictions to nurses' full scope of practice mainly applied to prescribing for nurses in an advanced role [76], which forced them to collaborate with or be supervised by a physician. Moreover, our analysis indicates that nurse's role implementation is dependent on the organizational setting in which it is embedded. Indeed, the decreased availability and retention of nurses are two phenomena predominantly seen in rural underserved areas, where lack of career opportunities and lower salaries compel nurses- especially newly hired ones-to relocate to other areas [77].

Consistent with previous findings [78], we show that lack of interprofessional collaboration and poor support from physicians and administrative staff has a negative impact on the implementation climate and healthcare provision, indicating that knowledge and beliefs of individuals belonging to an organization can influence individual acceptance of workforce change.
Overall, this review supports the notion that lack of role clarity among stakeholders is a significant and widespread barrier to optimal nurse's role implementation [78]. This phenomenon is similar to what observed in the general practice where physicians protecting their professional boundaries and expertise can cause tension and confusion in the workplace [9].

\section{Facilitators}

Major facilitators identified under the CFIR domains are linked to $i$ ) the characteristics of the intervention, $i i)$ the inner setting of the organization, and iii) the implementation process. Key factors include prior planning for role introduction and nurses' involvement in the early stage of role implementation. These findings further underscore the importance of the stakeholders' involvement in driving the implementation process and building consensus on the nurse's role [79]. More broadly, nurse's role implementation should be preceded by indepth reflections on the expected contribution of nurses to patient outcome achievement and team work [80].

With regard to challenges inherent in role development, job satisfaction and nurses' access to high-quality education are the two main themes emerging among RNs and NPs. This is in line with a previous study showing that the standardization of nursing educational requirements-especially for nurses with advanced roles in the primary healthcare setting, such as NPs-supports role enactment [76]. Of note, the same study also highlights the importance of providing more interprofessional training while increasing the practice component of education.

Consistent with previous literature $[78,81]$, we find that building collaborative relationships in the workplace favors nurse's role implementation and promotes nurses' job satisfaction. Collaborative working does not always emerge spontaneously, which is in good agreement with Contandriopoulos et al. [80]. From a nurse's perspective, respect, trust, and communication are the main pillars of successful doctor-nurse collaboration, as shown previously in the general practice [9]. Developing an effective collaboration between nurses and physicians may ultimately improve patient outcome thanks to the added value brought by nurses to the practice [82].

\section{Limitations}

Even though this integrative review provides a comprehensive and accurate overview of the main facilitators of and barriers to nurse's role implementation in the primary care setting. It is important to note that CFIR, used to selected constructs, identifies a list of factors within general domains that are believed to influence positively or negatively nurse's role implementation, but does not rank factors in order of importance. Thus, we 
recommend to always consider multiple factors when implementing nurse's role. In addition, although many aspects are transversal to the different countries involved in the study, the differences among contexts (e.g., political, social, cultural) and health systems make the results described herein non-standard. Another limitation is that the studies analyzed were published between 1996 and 2020. Thus, factors reported in studies published before or after this time period may not have been included. Lastly, as the factors contributing to nurse's role implementation are quite complex, we may have missed some additional factors due to the language restrictions used in the inclusion criteria.

\section{Conclusions}

From this integrative review, the following considerations emerge in a significant and transversal way: $i$ ) there is sub-optimal attention to the legislative and regulatory aspects governing the nursing profession; ii) there is only a partially complete regulation of the autonomy of the nursing profession; iii) there is paucity of studies on the role of professionals and various stakeholders in nurse's role development and implementation in primary care; iv) there is lack of recognition of the nurse's role and skills, especially within the multidisciplinary team; and $v$ ) there exist barriers to nurses' training opportunities and ongoing education.

Overall, nurse's role implementation appears to be a complex process influenced by numerous factors. Thus, there cannot be simple and linear recommendations to successfully develop and implement the nurse's role in primary care. In this regard, the Medical Research Council framework $[83,84]$ has been used to guide the development of complex interventions, especially those related to nurse's research and practice [85]. However, the fact that the facilitators may become barriers if not properly addressed poses some limitations to this approach. Indeed there is growing consensus on the need to consider-and simultaneously tackle-a number of factors influencing different domains (i.e., interprofessional, interpersonal, organizational, and systemic) when designing a tailored intervention. Likewise, our findings indicate that nurse's role implementation needs to be contextualized, looking at barriers and facilitators and involving the inputs from different stakeholders as well as the legislative and regulatory aspects specific to the country of residence. It is only through this dynamic and context-dependent implementation process that nurses will be employed to strengthen the resilience of national healthcare systems around the world.

\section{Abbreviations}

NCDs: Non-communicable diseases; WHO: World Health Organization; CFIR: Consolidating Framework for Research Implementation; APN: Advanced practice nurse; NP: Nurse practitioner, RN-registered nurse

\section{Supplementary Information}

The online version contains supplementary material available at https://doi. org/10.1186/s12912-021-00696-y.

Additional file 1. Search Strategy.

Additional file 2. Summary of key characteristics of the included studies.

Additional file 3. Facilitators and barriers identified by the studies mapped on to their corresponding CFIR domains and constructs.

\section{Acknowledgements}

Not applicable.

\section{Conflict of interest}

The authors declare that they have no conflicts of interest with respect to the research, authorship, and/or publication of this article and that they all agree with the final versions of this manuscript.

\section{Authors' contributions}

$E B$ and $A D M$ have set up the studio facility. EB and MB developed the search strategy. EB, AS and TLC independently reviewed titles and abstracts, assessed the inclusion criteria of all identified publications, and performed data extraction and quality assessment. ADM was consulted in case of conflicts. $\mathrm{ADM}$ and $\mathrm{MB}$ have contributed to formulate the methodological questions. EB and MB drafted the manuscript. All other authors (AS, TLC and BM) have made significant contributions to content-related questions and have read and edited the drafts. All authors agreed on the final manuscript.

\section{Funding}

This study was partially funded by the Italian Ministry of Education, University and Research (MIUR) program "Departments of Excellence 2018-2022", AGING Project - Department of Translational Medicine, Università del Piemonte Orientale.

Provenance and peer review

Not commissioned.

\section{Availability of data and materials}

Data is available upon reasonable request. The detailed results of the assessment of all barriers and facilitators are available upon reasonable request. All requests relating to data should be addressed to erica. busca@uniupo.it

\section{Declarations}

Ethics approval and consent to participate Not applicable.

Consent for publication Not applicable.

\section{Competing interests}

The authors declare that they have no competing interest.

\section{Author details}

${ }^{1}$ Department of Translational Medicine, University of Piemonte Orientale, Via P. Solaroli, 17, 28100 Novara, Italy. Functional Oncology Department Gastroenterology, Hospital "San Vincenzo" of Taormina, Contrada Sirina, 98039 Taormina, Italy. Emergency-Urgency Department, Hospital "Sant'Elia" of Caltanissetta, Via Cusmano,1, 93100 Caltanissetta, Italy. ${ }^{4}$ Humanitas University, Via Rita Levi Montalcini 4, Pieve Emanuele, 20090 Milan, Italy. ${ }^{5}$ Department of Translational Medicine, University of Piemonte Orientale, Direzione delle Professioni Sanitarie - A.O.U. Maggiore della Carità di Novara, Via P. Solaroli, 17, 28100 Novara, Italy. 
Received: 12 February 2021 Accepted: 1 September 2021 Published online: 16 September 2021

\section{References}

1. WHO. Global Health Estimates [Internet]. 2019. Available from: https://www. who.int/data/global-health-estimates

2. OECD. Health at a Glance: Europe 2020 [Internet]. 2020. Available from: https://www.oecd-ilibrary.org/social-issues-migration-health/health-at-a-gla nce-europe-2020_82129230-en

3. WHO. Noncommunicable diseases [Internet]. 2018. Available from: https:// www.who.int/news-room/fact-sheets/detail/noncommunicable-diseases

4. United Nations, Department of Economic and Social Affairs Population Division. World Population Ageing 2017 - Highlights (ST/ESA/SER.A/397). 2017.

5. WHO. Decade of healthy ageing: baseline report. Geneva: World Health Organization; 2020.

6. WHO. Global spending on health: a world in transition. Geneva: World Health Organization; 2019. (WHO/HIS/HGF/HFWorkingPaper/19.4).

7. Tahan HM. Essential Case Management Practices Amidst the Novel Coronavirus Disease 2019 (COVID-19) Crisis: Part 1: Tele-Case Management, Surge Capacity, Discharge Planning, and Transitions of Care. Prof Case Manag. 2020;25(5):248-66.

8. European Commission. THE ORGANISATION OF RESILIENT HEALTH AND SOCIAL CARE FOLLOWING THE COVID-19 PANDEMIC opinion of THE Expert Panel on effective ways of investing in health (EXPH) 2020.

9. Mclnnes S, Peters K, Bonney A, Halcomb E. An integrative review of facilitators and barriers influencing collaboration and teamwork between general practitioners and nurses working in general practice. J Adv Nurs. 2015;71(9):1973-85. https://doi.org/10.1111/jan.12647.

10. OECD. Health Working Paper No. 54 Nurses in Advanced roles: a description and evaluation of experiences in 12 developed countries. 2010.

11. Freund T, Everett C, Griffiths P, Hudon C, Naccarella L, Laurant M. Skill mix, roles and remuneration in the primary care workforce: who are the healthcare professionals in the primary care teams across the world? Int J Nurs Stud. 2015;52(3):727-43. https://doi.org/10.1016/j.jjurstu.2014.11.014.

12. Supper I, Catala O, Lustman M, Chemla C, Bourgueil Y, Letrilliart L. Interprofessional collaboration in primary health care: a review of facilitators and barriers perceived by involved actors. J Public Heal (United Kingdom). 2015;37(4):716-27.

13. Karimi-Shahanjarini A, Shakibazadeh E, Rashidian A, Hajimiri K, Glenton C, Noyes J, et al. Barriers and facilitators to the implementation of doctor-nurse substitution strategies in primary care: A qualitative evidence synthesis. Cochrane Database Syst Rev. 2019;4(4).

14. WHO. Declaration of Astana Global conference on primary health care. Astana: World Health Organization; 2018.

15. Grant J, Lines L, Darbyshire P, Parry Y. How do nurse practitioners work in primary health care settings? A scoping review. Int J Nurs Stud. 2017;75:517. https://doi.org/10.1016/j.ijnurstu.2017.06.011.

16. Whittemore R, Knafl K. The integrative review: updated methodology. J Adv Nurs. 2005 Dec;52(5):546-53. https://doi.org/10.1111/j.1365-2648.2005.03621.x.

17. Moher D, Liberati A, Tetzlaff J, Altman DG. Preferred reporting items for systematic reviews and Meta-analyses: the PRISMA statement. PLoS Med. 2009;6(7):e1000097. https://doi.org/10.1371/journal.pmed.1000097.

18. EXPH (EXpert Panel on effective ways of investing in Health), Report on Definition of a frame of reference in relation to primary care with a special emphasis on financing systems and referral systems, 10 July 2014.

19. Damschroder LJ, Aron DC, Keith RE, Kirsh SR, Alexander JA, Lowery JC. Fostering implementation of health services research findings into practice: a consolidated framework for advancing implementation science. Implement Sci. 2009;4(1):50. https://doi.org/10.1186/1748-5908-4-50.

20. Drennan VM. More care out of hospital? A qualitative exploration of the factors influencing the development of the district nursing workforce in England. J Health Serv Res Policy. 2019;24(1):11-8. https://doi.org/10.1177/13 55819618769082.

21. Carr J, Armstrong S, Hancock B, Bethea J. GPs' perceptions of the nurse practitioner role in primary care. Br J Community Nurs. 2002;7(8):408-13. https://doi.org/10.12968/bjcn.2002.7.8.10646.

22. Clancy A, Svensson T. Perceptions of public health nursing practice by municipal health officials in Norway. Public Health Nurs. 2009;26(5):412-20. https://doi.org/10.1111/j.1525-1446.2009.00799.x.
23. Martin-Misener R, Reilly SM, Vollman AR. Defining the role of primary health care nurse practitioners in rural Nova Scotia. Can J Nurs Res. 2010;42(2):30-47.

24. De Guzman A, Ciliska D, DiCenso A. Nurse practitioner role implementation in Ontario public health units. Can J Public Heal. 2010;101(4):309-13. https:// doi.org/10.1007/BF03405292.

25. Reutter LI, Ford JS. Perceptions of public health nursing: views from the field. J Adv Nurs. 1996;24(1):7-15. https://doi.org/10.1046/j.1365-2648.1996.01681.x.

26. Adams S, Carryer J, Nz F. Establishing the nurse practitioner workforce in rural New Zealand: barriers and facilitators. J Prim Heal Care. 2019;11(2): 152-9. https://doi.org/10.1071/HC18089.

27. Athey EK, Leslie MS, Briggs LA, Park J, Falk NL, Pericak A, et al. How important are autonomy and work setting to nurse practitioners' job satisfaction? J Am Assoc Nurse Pract. 2016;28(6):320-6. https://doi.org/10.1 002/2327-6924.12292.

28. Donelan K, DesRoches CM, Dittus RS, Buerhaus P. Perspectives of physicians and nurse practitioners on primary care practice. N Engl J Med. 2013; 368(20):1898-906. https://doi.org/10.1056/NEJMsa1212938.

29. Boman E, Glasberg A-L, Levy-Malmberg R, Fagerstrom L. "Thinking outside the box": advanced geriatric nursing in primary health care in Scandinavia. BMC Nurs. 2019;18(1):25. https://doi.org/10.1186/s12912-019-0350-2.

30. Faraz A. Facilitators and barriers to the novice nurse practitioner workforce transition in primary care. J Am Assoc Nurse Pract. 2019;31(6):364-70. https://doi.org/10.1097/JXX.0000000000000158.

31. Kraus E, DuBois JM. Knowing your limits: a qualitative study of physician and nurse practitioner perspectives on NP Independence in primary care. J Gen Intern Med. 2017;32(3):284-90. https://doi.org/10.1007/s11606-016-3896-7.

32. Drury $V$, Francis $K$, Dulhunty $G$. The lived experience of rural mental health nurses. Online J Rural Nurs Health Care. 2005;5(1):19-27. https://doi.org/1 0.14574 /ojrnhc.v5i1.254.

33. Kipping CJ. Exploring mental health nurses' expectations and experiences of working in the community. J Clin Nurs. 1998;7(6):531-8. https://doi.org/10.1 046/j.1365-2702.1998.00182.x.

34. Crawford P, Carr J, Knight A, Chambers K, Nolan P. The value of community mental health nurses based in primary care teams: "Switching the light on in a cellar". J Psychiatr Ment Health Nurs. 2001;8(3):213-20. https://doi.org/1 0.1046/j.1365-2850.2001.00384.x.

35. Carryer J, Adams S. Nurse practitioners as a solution to transformative and sustainable health services in primary health care: a qualitative exploratory study. Collegian. 2017;24(6):525-31. https://doi.org/10.1016/j.colegn.2016.12.001.

36. Parfitt BA, Cornish F. Implementing family health nursing in Tajikistan: from policy to practice in primary health care reform. Soc Sci Med. 2007;65(8): 1720-9. https://doi.org/10.1016/j.socscimed.2007.06.007.

37. Hansen-Turton T, Ware J, Bond L, Doria N, Cunningham P. Are managed care organizations in the United States impeding the delivery of primary care by nurse practitioners? A 2012 update on managed care organization credentialing and reimbursement practices. Popul Health Manag. 2013;16(5): 306-9. https://doi.org/10.1089/pop.2012.0107.

38. Poghosyan L, Nannini A, Smaldone A, Clarke S, O'Rourke NC, Rosato BG, et al. Revisiting scope of practice facilitators and barriers for primary care nurse practitioners: a qualitative investigation. Policy Polit Nurs Pract. 2013; 14(1):6-15. https://doi.org/10.1177/1527154413480889.

39. Sullivan-Bentz M, Humbert J, Cragg B, Legault F, Laflamme C, Bailey PH, et al. Supporting primary health care nurse practitioners' transition to practice. Can Fam Physician. 2010;56(11):1176-82.

40. Weiland SA. Understanding nurse practitioner autonomy. J Am Assoc Nurse Pract. 2015;27(2):95-104. https://doi.org/10.1002/2327-6924.12120.

41. Price A, Williams A. Primary care nurse practitioners and the interface with secondary care : a qualitative study of referral practice. J Interprof Care. 2003;17(3):239-50. https://doi.org/10.1080/1356182031000122861.

42. Lovink MH, van Vught AJAH, Persoon A, Schoonhoven L, Koopmans RTCM, Laurant MGH. Skill mix change between general practitioners, nurse practitioners, physician assistants and nurses in primary healthcare for older people: a qualitative study. BMC Fam Pract. 2018;19(1):51. https://doi.org/1 0.1186/s12875-018-0746-1.

43. Plews $C$, Billingham $\mathrm{K}$, Rowe A. Public health nursing: barriers and opportunities. Heal Soc Care Community. 2000;8(2):138-46. https://doi.org/1 0.1046/j.1365-2524.2000.00231.x.

44. Carryer J, Boddy J, Budge C. Rural nurse to nurse practitioner: an ad hoc process. J Prim Health Care. 2011;3(1):23-8. https://doi.org/10.1071/HC11023.

45. Fletcher CE, Baker SJ, Copeland LA, Reeves PJ, Lowery JC. Nurse practitioners' and physicians' views of NPs as providers of primary care to 
veterans: health policy and systems. J Nurs Scholarsh. 2007;39(4):358-62. https://doi.org/10.1111/j.1547-5069.2007.00193.x.

46. Gysin S, Sottas B, Odermatt M, Essig S. Advanced practice nurses' and general practitioners' first experiences with introducing the advanced practice nurse role to Swiss primary care: a qualitative study. BMC Fam Pract. 2019;20(1, 1). https://doi.org/10.1186/s12875-019-1055-z.

47. Fletcher CE, Copeland LA, Lowery JC, Reeves PJ. Nurse practitioners as primary care providers within the VA. Mil Med. 2011;176(7):791-7. https:// doi.org/10.7205/MILMED-D-10-00329.

48. Gould ON, Johnstone D, Wasylkiw L. Nurse practitioners in Canada: beginnings, benefits, and barriers. J Am Acad Nurse Pract. 2007;19(4):16571. https://doi.org/10.1111/j.1745-7599.2007.00210.x.

49. Faraz A. Novice nurse practitioner workforce transition and turnover intention in primary care. J Am Assoc Nurse Pract. 2017;29(1):26-34. https:// doi.org/10.1002/2327-6924.12381.

50. Hunter KF, Murphy RS, Babb M, Vallee C. Benefits and challenges faced by a nurse practitioner working in an Interprofessional setting in rural Alberta. Nurs Leadersh (Tor Ont). 2016;29(3):61-70. https://doi.org/10.12927/cjnl.2016.24893.

51. Main R, Dunn N, Kendall K. "Crossing professional boundaries": barriers to the integration of nurse practitioners in primary care. Educ Prim Care. 2007; 18(4):480-7. https://doi.org/10.1080/14739879.2007.11493578.

52. van der Biezen $M$, Derckx E, Wensing M, Laurant M. Factors influencing decision of general practitioners and managers to train and employ a nurse practitioner or physician assistant in primary care: a qualitative study. BMC Fam Pract. 2017;18(1):16. https://doi.org/10.1186/s12875-017-0587-3.

53. Lindblad E, Hallman EB, Gillsjö C, Lindblad U, Fagerström L. Experiences of the new role of advanced practice nurses in Swedish primary health care-a qualitative study. Int J Nurs Pract. 2010;16(1):69-74. https://doi.org/10.1111/ j.1440-172X.2009.01810.x

54. Wilson A, Pearson D, Hassey A. Barriers to developing the nurse practitioner role in primary care - the GP perspective. Fam Pract. 2002;19(6):641-6. https://doi.org/10.1093/fampra/19.6.641.

55. Côté N, Freeman A, Jean E, Denis J-L. New understanding of primary health care nurse practitioner role optimisation: the dynamic relationship between the context and work meaning. BMC Health Serv Res. 2019;19(1):882. https://doi.org/10.1186/s12913-019-4731-8

56. Jean E, Sevilla Guerra S, Contandriopoulos D, Perroux M, Kilpatrick K, Zabalegui A. Context and implementation of advanced nursing practice in two countries: an exploratory qualitative comparative study. Nurs Outlook. 2019;67(4):365-80. https://doi.org/10.1016/j.outlook.2019.02.002.

57. Rapport F, Maggs C. Measuring care : the case of district nursing. J Adv Nurs. 1997;25(4):673-80. https:/doi.org/10.1046/.1365-2648.1997.1997025673.x.

58. Burke T. O' Neill C. community nurses working in piloted primary care teams: Irish Republic. Br J Community Nurs. 2010;15(8):398-404. https://doi. org/10.12968/bjcn.2010.15.8.74867.

59. Burgess J, Martin A, Senner W. A framework to assess nurse practitioner role integration in primary health care. Can J Nurs Res. 2011;43(1):22-40.

60. Dunt DR, Temple-Smith MJ, Johnson KA. Nursing outside hospitals: the working experience of community nurses: job characteristics. Int J Nurs Stud. 1991;28(1):27-37. https://doi.org/10.1016/0020-7489(91)90047-7.

61. Burgess J, Purkis ME. The power and politics of collaboration in nurse practitioner role development. Nurs Inq. 2010;17(4):297-308. https://doi. org/10.1111/j.1440-1800.2010.00505.x.

62. Ljungbeck B, Sjögren FK. Advanced nurse practitioners in municipal healthcare as a way to meet the growing healthcare needs of the frail elderly: a qualitative interview study with managers, doctors and specialist nurses. BMC Nurs. 2017;16(1). https://doi.org/10.1186/s12912-017-0258-7.

63. Zug KE, Cassiani SHDB, Pulcini J, Bassalobre Garcia A, Aguirre-Boza F, Park J. Enfermagem de prática avançada na América Latina e no Caribe: Regulação, educação e prática. Rev Lat Am Enfermagem. 2016;24(0). https://doi.org/1 0.1590/1518-8345.1615.2807.

64. Conger M, Plager K. Advanced nursing practice in rural areas: connectedness versus disconnected: EBSCOhost. Online J Rural Nurs Health Care. 2008;8(1):24-38. https://doi.org/10.14574/ojrnhc.v8i1.127.

65. Drennan V, Goodman C, Manthorpe J, Davies S, Scott C, Gage H, et al. Establishing new nursing roles: a case study of the English community matron initiative. 2011;20(19-20):2948-57. https://doi.org/10.1111/j.1365-2 702.2010.03643.X.

66. Mackay B. General practitioners' perceptions of the nurse practitioner role: an exploratory study. N Z Med J. 2003;116(1170):U356.
67. Perry C, Thurston M, Killey M, Miller J. The nurse practitioner in primary care: alleviating problems of access? Br J Nurs. 2005;14(5):255-9. https://doi.org/1 0.12968/bjon.2005.14.5.17659.

68. Craswell A, Dwyer T. Reasons for choosing or refusing care from a nurse practitioner: results from a national population-based survey. J Adv Nurs. 2019;75(12):3668-76. https://doi.org/10.1111/jan.14176.

69. Parker R, Forrest L, Ward N, McCracken J, Cox D, Derrett J. How acceptable are primary health care nurse practitioners to Australian consumers? Collegian. 2013;20(1):35-41. https://doi.org/10.1016/j.colegn.2012.03.001.

70. McCullough K, Whitehead L, Bayes S, Williams A, Cope V. The delivery of primary health care in remote communities: a grounded theory study of the perspective of nurses. Int J Nurs Stud. 2020;102:103474. https://doi.org/1 0.1016/j.jinurstu.2019.103474.

71. Domm E, Urban AM. Public health nurse perceptions of evolving work and how work is managed: A qualitative study. J Nurs Manag. 2020;28(8):2017-24. https://doi.org/10.1111/jonm.13058.

72. Poghosyan L, Norful AA, Martsolf GR. Organizational structures and outcomes of newly hired and experienced nurse practitioners in New York state. Nurs Outlook. 2017;65(5):607-14. https://doi.org/10.1016/j.outlook.2017.03.001.

73. Carr SM. Refocusing health visiting - sharpening the vision and facilitating the process. J Nurs Manag. 2005;13(3):249-56. https://doi.org/10.1111/j.13 65-2834.2004.00529.x.

74. MacDonald JM. Higher level practice in community nursing: part two. Nurs Stand. 2005;20(10):41-9. https://doi.org/10.7748/ns2005.11.20.10.41.c4004.

75. Jarrell L. Professional development and mentorship needs of nurse practitioners. J Nurses Prof Dev. 2016;32(1):26-32. https://doi.org/10.1097/ NND. 0000000000000160

76. DiCenso A, Bryant-Lukosius D, Martin-Misener R, Donald F, Abelson J, Bourgeault I, et al. Factors enabling advanced practice nursing role integration in Canada. Nurs Leadersh (Tor Ont). 2010;23 Spec No:211-38.

77. Yang Y, Liu YH, Liu JY, Zhang HF. The impact of work support and organizational career growth on nurse turnover intention in China. Int J Nurs Sci. 2015;2(2):134-9. https://doi.org/10.1016/j.ijnss.2015.04.006.

78. Torrens C, Campbell P, Hoskins G, Strachan H, Wells M, Cunningham M, et al. Barriers and facilitators to the implementation of the advanced nurse practitioner role in primary care settings: a scoping review. Int J Nurs Stud. 2020;104.

79. Sangster-Gormley E, Martin-Misener R, Downe-Wamboldt B, Dicenso A. Factors affecting nurse practitioner role implementation in Canadian practice settings: an integrative review. J Adv Nurs. 2011;67(6):1178-90. https://doi.org/10.1111/j.1365-2648.2010.05571.x.

80. Contandriopoulos D, Brousselle A, Dubois CA, Perroux M, Beaulieu MD, Brault I, et al. A process-based framework to guide nurse practitioners integration into primary healthcare teams: Results from a logic analysis Organization, structure and delivery of healthcare. BMC Health Serv Res. 2015;15(1).

81. Poghosyan L, Liu J, Shang J, D’Aunno T. Practice environments and job satisfaction and turnover intentions of nurse practitioners: implications for primary care workforce capacity. Health Care Manag Rev. 2017;42(2):162-71. https://doi.org/10.1097/HMR.0000000000000094.

82. Matthys $E$, Remmen R, Van Bogaert P. An overview of systematic reviews on the collaboration between physicians and nurses and the impact on patient outcomes: what can we learn in primary care? BMC Fam Pract. 2017;18(1). https://doi.org/10.1186/s12875-017-0698-x.

83. Campbell M, Fitzpatrick R, Haines A, Kinmonth AL, Sandercock P, Spiegelhalter $\mathrm{D}$, et al. Framework for design and evaluation of complex interventions to improve health. Br Med J BMJ Publishing Group. 2000;321:694-6.

84. Craig P, Dieppe P, Macintyre S, Mitchie S, Nazareth I, Petticrew M. Developing and evaluating complex interventions: the new Medical Research Council guidance. BMJ. 2008;337(7676):979-83. https://doi.org/1 0.1136/bmj.a1655

85. Corry M, Clarke M, While AE, Lalor J. Developing complex interventions for nursing: a critical review of key guidelines. J Clin Nurs. 2013;22(17-18):2366-86. https://doi.org/10.1111/jocn.12173.

\section{Publisher's Note}

Springer Nature remains neutral with regard to jurisdictional claims in published maps and institutional affiliations. 